\title{
An examination into some variables said to affect serial learning
}

\author{
E. J. CAPALDI, TIMOTHY M. NAWROCKI, DANIEL J. MILLER, and DONNA R. VERRY \\ Purdue University, West Lafayette, Indiana
}

\begin{abstract}
In each of three serial learning investigations, rats in a runway were given varying numbers of $0.045-\mathrm{g}$ food pellets in a fixed order. Serial learning was indexed by faster running to larger than to smaller reward quantities. It has been suggested by Hulse (Animal Learning \& Behavior, $1980,8,689-690$ ) and by Roitblat (Behavioral Brain Sciences, 1982, 5, 353-371) that differences between two or more serial learning groups that have been obtained under one set of specified ex. perimental conditions may be completely reversed or eliminated under another set of specified experimental conditions. In each of the three investigations reported here, we examined series that had been compared in previous investigations, employing, however, experimental conditions that, according to Hulse and to Roitblat, should produce results different from those obtained previously. In each of the three investigations reported here, the groups differed as they had previously. The findings obtained in this report suggest that none of the following variables is critical to the results obtained in serial learning investigation in the sense suggested by Hulse and Roitblat: the number of items contained in the series, the number of times the series is presented each day, the temporal interval elapsing between items, and the temporal interval elapsing between series presentations. The implications of the present findings for the rule-encoding view of Hulse and his coworkers and for the memory-discrimination learning view of Capaldi and his coworkers are examined.
\end{abstract}

In a serial learning task, items are presented in a fixed order which must be learned or remembered. Although in human serial learning investigations, the items are often words or digits, in many recent animal studies they were different numbers of $0.045-\mathrm{g}$ food pellets presented in the goalbox of a runway, with serial learning being indexed by faster running to larger than to smaller retward quantities, particularly to a terminal 0 -pellet item. It has been suggested that the differences obtained between two or more serial learning groups under one set of specified experimental conditions may be completely reversed or eliminated under another set of specified experimental conditions. This view, originally suggested by Hulse (1980), was subsequently endorsed by some (e.g., Roitblat, 1982; see also Roitblat, Pologe, \& Scopatz, 1983) and questioned by others (e.g., Capaldi, Verry, \& Davidson, 1980b). The view was tested in the three experiments reported here.

According to Hulse (1980), what an animal learns in a serial task (cognitions vs. associations), and therefore how it performs, will differ depending on a number of variables: the number of items contained in the series, the amount of training given on the series, the number of times the series is presented each day, the interval that separates repetitions of series, called here the interseries interval (ISI), and the interval that elapses between presen-

This research was supported in part by NSF Grant BNS 80-001171 to E. J. Capaldi and by a David Ross Fellowship to Timothy $\mathbf{M}$. Nawrocki.

The authors' mailing address is: Department of Psychological Sciences, Purdue University, West Lafayette, IN 47907. tations of the items, the interrun interval (IRI). Roitblat et al. (1983) emphasize that what is learned in a serial task is affected by IRI and the number of items in the series, and in their Experiment 2 they supplied evidence that, they suggested, indicated that the number of series presentations per day was unimportant. The adequacy of this conclusion may be doubted, however, since, in their Experiment 2, IRI and the number of series presentations per day were confounded. In any event, Roitblat et al. (1983) considered IRI to be important because, in their Experiment 1, they failed to obtain differences between two serial learning groups at a 4-5 min IRI, although Hulse and Dorsky (1977) earlier had obtained such differences at a 15-sec IRI. We regard Roitblat et al.'s data as inconclusive, however, since Roitblat et al., in their Experiment 1 , failed to completely replicate the findings previously reported by Hulse and Dorsky (1977) for a 15-sec IRI and, generally speaking, Roitblat et al.'s rats appeared to learn poorly, a matter considered in greater detail in our present Experiment 3. Aside from the data of Roitblat et al. (1983), which seem to be questionable in several respects, no direct experimental evidence is available to support the view of Hulse and Roitblat (see, e.g., Capaldi \& Molina, 1979; Capaldi, Verry, \& Davidson, 1980a, 1980b).

Hulse (1980) suggested that rats learn series cognitively when information load is high: otherwise series are learned by "rote," associatively. Information load is increased by employing series containing many items, by presenting the items at a relatively rapid rate, and by presenting the series repeatedly each day with an inter- 
val of no more than 10-15 min elapsing between series presentations. When an animal learns a series cognitively, it encodes the rule structure of the series, simpler series being learned more rapidly than more complex ones. A series in which each successive item is smaller than the previous one-a monotonic decreasing series-is, according to this view, simpler and thus should be learned more rapidly than one in which items increase as well as decrease-a nonmonotonic series. Numerous exceptions to this generalization have been reported by Capaldi and Molina (1979) and Capaldi et al. (1980a). However, the experimental conditions employed by Capaldi and his coworkers differed in a variety of respects from those employed in Hulse's laboratory (see, e.g., Hulse, 1980). Hulse (1980) suggested that the experimental conditions employed in Capaldi's laboratory were favorable to forming associations between items, whereas the experimental conditions employed in his laboratory were favorable to encoding the rule structure of a series. According to this view, a monotonic series, for example, will be learned more easily than, for example, a nonmonotonic series if a rule-learning strategy is employed. But if the series are learned associatively, then faster learning of a monotonic than of a nonmonotonic series might not occur; indeed, the opposite might occur.

If Hulse and Roitblat are correct, it follows that differences obtained between serial learning groups in previous investigations under a given set of specified experimental conditions (those favorable to encoding rules) can be completely reversed or eliminated if a different set of specified experimental conditions is employed (those promoting associative learning). It was this hypothesis that was tested here. In each of three investigations reported here, we examined series that had been compared in previous investigations. The comparisons were made, however, employing different experimental conditions, conditions which, according to Hulse and Roitblat, should produce results different from those obtained previously.

\section{EXPERIMENT 1}

Hulse and Dorsky (1977) found better serial learning when the relatively long five-item monotonic decreasing series 14-7-3-1-0 was employed than when the five-item weakly monotonic series 14-5-5-1-0 was employed, the 0 -pellet item being much better anticipated under the former than under the latter series. Hulse and Dorsky (1977) employed a 15-sec IRI, a 15-min ISI, four presentations of each series each day, and a total of 44 series presentations overall. Capaldi and Molina (1979), when comparing shorter four-item series in their Experiment 1, found that two weakly monotonic series, $15-15-0-0$ and 14-14-2-0, were learned better than a strongly monotonic series, 15-10-5-0. Capaldi and Molina (1979) employed an IRI of 4-5 min, only one series presentation each day (and thus an ISI of $24 \mathrm{~h}$ ), and a total of only 12 series presentations. The failure of the 15-10-5-0 strongly monotonic series to produce better serial learning than either of the two weakly monotonic series, $15-15-0-0$ and $14-$
14-2-0, in Capaldi and Molina's (1979) investigation is, according to Hulse (1980), not inconsistent with his ruleencoding view, which suggests that series with simpler rule structures should be learned more rapidly than series with more complex rule structures. Rather, it comes about, Hulse has suggested, because the experimental conditions employed by Capaldi and Molina (1979) resulted in the series' being learned associatively, one item in the series being the stimulus for the next. If this view is correct, then the series employed by Capaldi and Molina (1979) in their Experiment 1 should produce results in conformity with a rule-learning approach employing the experimental conditions of Hulse and Dorsky (1977), which are regarded as favorable for rule encoding. In Experiment 1 , we compared the strongly monotonic $15-10$ 5-0 series with the weakly monotonic $15-15-0-0$ series, employing an IRI of 15-20 sec, an ISI of 10-15 min, four presentations of each series each day, and a total of 42 series presentations.

\section{Subjects}

\section{Method}

The subjects were 12 naive male albino rats purchased from the Holtzman Co., Madison, Wisconsin. They were 77 days old on arrival at the laboratory

\section{Apparatus}

The apparatus was a straight gray runway, $194.94 \mathrm{~cm}$ long, $9.0 \mathrm{~cm}$ wide, and enclosed by $12.5-\mathrm{cm}$ sides. It was covered by a wire-mesh top on a hinged frame. The startbox and goalbox were 22.86 and $36.19 \mathrm{~cm}$ long, respectively, and closed off by brass guillotine doors. Raising the startbox door started a completely silent 0.01 -sec digital clock, which was stopped when a photobeam located $158.75 \mathrm{~cm}$ beyond the startbox door and $6.35 \mathrm{~cm}$ in front of the goalcup was broken by the rat. Pellets $(0.045-\mathrm{g}$ Noyes) could be placed in a goalcup, $4.0 \mathrm{~cm}$ in diameter and $1.5 \mathrm{~cm}$ in depth, cut into a $6.5 \times 9.0 \times 4.5 \mathrm{~cm}$ rectangular wooden block that was located at the end of the runway. The pellets were not visible prior to the breaking of the photobeam.

\section{Procedure}

Pretraining. On arrival at the laboratory, the rats were caged individually and allowed ad-lib food and water for 12, 23, and 34 days for Replications 1,2, and 3, respectively, before being placed on food deprivation (14-g Wayne Lab Blox) on the 1st day of pretraining. The pretraining and following experimental procedures were identical for the three replications. On Days 1-6, each rat was handled for $1 \mathrm{~min}$ and then fed the daily ration in the home cage. On Day 7, each rat was handled, fed 15 pellets in the home cage, and then fed the daily ration. Throughout the experiment, all pellets eaten by the rat were subtracted from the daily ration. On Days 8-10, each rat was exposed to the unbaited runway for $2 \mathrm{~min}$, during which the startbox and goalbox doors were lowered briefly and then raised after the first minute of exploration to acquaint the rat with these sounds. After all rats had received this exploration time, they were returned to their home cages, fed 15 pellets each, and then fed the daily ration. On Days 11-12, each rat received one 15-pellet run in the alley. The rat was placed in the startbox, the doors were opened approximately $3 \mathrm{sec}$ later, and the rat was allowed to run to the goalbox for the 15 pellets (placed in the goalcup), after which the doors were closed. The rat was allowed $60 \mathrm{sec}$ to traverse the alley. If it failed to reach the goal in this time, it was picked up and placed gently in the goalbox to receive the pellets. After all rats had received the 15-pellet run, they were fed the daily ration.

Training. Training began on Day 13 and lasted 11 days. There were two groups of two rats each per replication; they were as- 
signed randomly on Day 1 of training. All four rats were placed into holding cages, water being freely available, and brought into the experimental room. Both groups received four series of four ordered runs each. Runs were either rewarded (a number of pellets) or nonrewarded (no pellets and 15-sec goalbox confinement). The strongly monotonic group, Group SM, received the ordered runs of $15,10,5$, and 0 pellets. The weakly monotonic group, Group WM, received the ordered runs of $15,15,0$, and 0 pellets. The rats received only two such series presentations on Day 1 of training and all four series presentations on Days 2-11 of training. A rat received all four runs of a series before the next rat was run. All rats received the runs of their first series before any rat received the runs of its second series, and so on, until all four series presentations were given. The rats were confined to the holding cages between runs. Running orders of the rats were randomized daily, with the same order used for all four series presentations within a day. The ISI was about $15 \mathrm{~min}$. The IRI was about $15-20 \mathrm{sec}$, depending on the time taken by the experimenter to read the clock, record the time, bait the goalcup, and so forth.

A run began with the removal of the rat from the holding cage and its placement in the startbox. Approximately $3 \mathrm{sec}$ later, the startbox door was raised. The rat was given a maximum of $60 \mathrm{sec}$ to traverse the alley. If this time elapsed without the rat's reaching the goal, the animal was removed and placed gently in the goalbox. On rewarded runs, the rat was removed after it had eaten all of the food pellets; on nonrewarded runs, it was removed after $15 \mathrm{sec}$. A cloth-lined cup was used to bait the goalcup, and an open canister of pellets was placed at the end of the alley to control for noise and odor cues. The rats were fed their daily ration about 10 min after all of them had completed runway training.

\section{Results}

Figure 1 shows, for Groups SM and WM, the running speeds to each item of their respective series on Day 1 of training and thereafter in blocks of 2 days. As Figure 1 shows, the two groups performed virtually identically on Day 1. However, with training, Group WM anticipated the 0-pellet item better than did Group SM. Over the last two blocks of training, for example, the two groups ran equally rapidly to the first two items of their respective series, but for Items 3 and 4, Group WM ran more slowly than Group SM. On Day 1, the groups failed to differ $(F<1)$, as did the groups $\times$ items interaction $[F(3,18)$ $=1.62, \mathrm{p}>.05]$. An ANOVA over the remaining data shown in Figure 1 revealed that Group WM ran signifi-

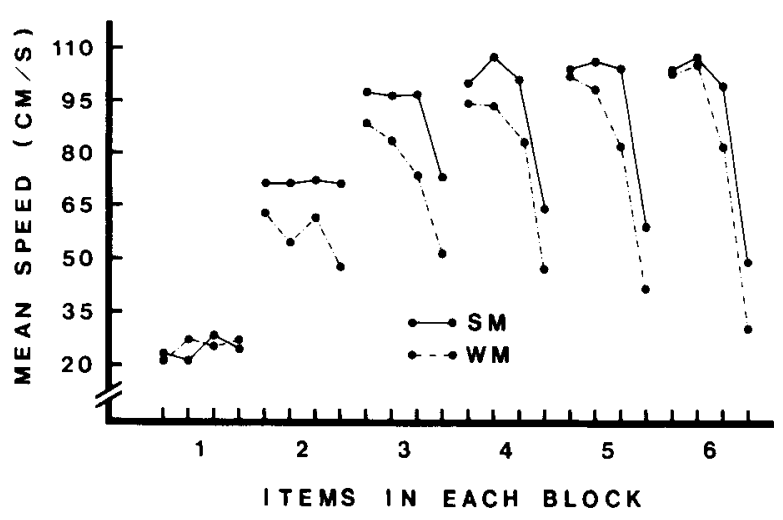

Figure 1. Running speeds for Groups SM and WM to each item of their series on Day 1 and thereafter in blocks of 2 days. In each block, the items are plotted either in the order 15-15-0-0 (Group WM) or in the order 15-10-5-0 (Group SM). cantly more slowly than Group SM $[F(1,6)=7.89$, p < $.05]$, that running speed to the items differed substantially $[F(3,18)=133.44, p<.001]$, and, importantly, that the groups $\times$ items interaction was significant $[F(3,18)=$ $4.35, \mathrm{p}<.02$ ]. Subsequent Newman-Keuls tests based on a breakdown of the groups $\times$ items interaction revealed that Group WM ran more slowly to the terminal 0-pellet item than did Group SM ( $<<.01)$. In addition, Group WM ran more slowly to Item 3 of its series ( 0 pellets) than Group SM did to Item 3 of its series ( 5 pellets, $p<.05$ ); the running speeds of the groups did not differ for either of the initial two items of the series. As for within-groups differences, Group SM ran more slowly to its 0-pellet item than to any other (ps $<.01$ ), but no other differences were significant; Group WM ran more slowly to its terminal 0-pellet item than any other (ps < .01 ) and more slowly to Item 3, also a 0 -pellet item, than to either of the initial two items (ps $<.05$ ), but no other differences were significant.

\section{Discussion}

In Experiment 1, Group SM, which received the series 15-10-5-0, anticipated its 0-pellet item and Group WM, which received the series 15-15-0-0, anticipated both of its 0-pellet items. Importantly, Group WM ran more slowly to its terminal 0-pellet item than Group SM did to its 0-pellet item. Capaldi and Molina (1979) also used the 15-10-5-0 and 15-15-0-0 series, but under the following different experimental conditions: one presentation of the series daily, as opposed to four daily here; an IRI of about 4-5 min, as opposed to about 15-20 sec here; an ISI of $24 \mathrm{~h}$, as opposed to about $15 \mathrm{~min}$ here; and a total of only 12 series presentations, as opposed to 42 series presentations here. The results obtained here were virtually identical to those reported by Capaldi and Molina, with one exception: the initial 0-pellet item of the 15-15$0-0$ series was not anticipated in the earlier investigation. Such anticipation was obtained here because, we suspect, of the more extensive training employed, with slow running to the initial 0-pellet item of the 15-15-0-0 series developing with training in Experiment 1 . The important finding obtained in Experiment 1, however, was that the direction of the difference between Groups WM and SM was the same here, under conditions said to be favorable for rule encoding, as had been previously obtained by Capaldi and Molina (1979), who were said to have employed conditions favorable for associative learning.

\section{EXPERIMENT 2}

In their Experiment 2, which employed one series presentation per day and a 4-5 min IRI, Capaldi and Molina (1979) compared short three-item series, and obtained better tracking of 0 pellets under the strongly nonmonotonic 1-29-0 series than under the strongly monotonic 20 10-0 series. According to Hulse (1980), these results are not inconsistent with his rule-encoding model, because the IRI was 4-5 min, only one series presentation was 
given each day, and possibly also because the series contained only three items. Short series contain only a few exemplars of the rule, and thus may not be learned by employing a rule-learning strategy. Roitblat et al. (1983) also attached special importance to short series, suggesting that the way in which they are learned is different from the way in which long series are learned. Many of the series employed by Capaldi et al. (1980b), which have been said to be inconsistent with the rule-encoding model, were short. For example, one group received the two series $15-10$ and 20-0, another group the two series 1-10 and $20-0$. In the former group, both series were consistent (both decreased), whereas in the latter group, the two series were inconsistent (one increased and the other decreased). Nevertheless, the 0 -pellet item of the 20-0 series was better anticipated by the group with the inconsistent rule than by the group with the consistent rule.

But Fountain, Evenson, and Hulse (1983) have suggested that rats can encode rules even in connection with short series if experimental conditions favorable for rule encoding are employed. They reported better tracking of the terminal 0-pellet item in the strongly monotonic series 18-1-0 than in the strongly nonmonotonic $1-18-0$ series, employing a 10-15-sec IRI, a 10-15-min ISI, and four series presentations each day. Concerning this finding, they state that "even for short patterns, rats opted for a rule-learning strategy to learn and remember the formally simple patterns" (p. 191). It would appear to follow from the treatment of Hulse (1980) and of Roitblat et al. (1983) that, if the 18-1-0 and 1-18-0 series were compared under the same experimental conditions as those empioyed by Capaldi and Molina (1979) in connection with the 20-10-0 and 1-29-0 series, the same results would be obtained, that is, the nonmonotonic group should exhibit better serial learning than the monotonic group. In Experiment 2, the 18-1-0 and 1-18-0 series were compared under conditions not deemed favorable for rule encoding, with each series being presented only once each day at either a $15-20-\mathrm{sec}$ or a 4-min IRI. The 4-min IRI condition is less favorable to rule encoding than is the $15-20$-sec IRI condition, but neither is favorable, because only one series presentation was used each day.

\section{Subjects}

The subjects were 20 rats of the same description as in Experiment 1 . They were about 90 days old at the start of training.

\section{Apparatus.}

The apparatus was the same as that employed in Experiment 1.

\section{Procedure}

Pretraining. Upon arrival at the lab, the rats were caged individually and given unlimited access to food and water for 12 days. On Day 1 of pretraining, all food was removed from the home cages and the rats were placed on a 14-g/day deprivation schedule, consisting of Wayne Lab Blox minus any pellets given. Water remained available at all times. Each rat was handled for $1 \mathrm{~min}$ on Days 1-7 and given $2 \mathrm{~min}$ of unbaited alley exploration on Days 8-10. In addition, on Days 7-10, each rat received 18 0.045-g Noyes food pellets in jar lids in the home cage and a reduced ration of Lab Blox.
On Days 11-12, each rat received a single run in the alley, terminating in 18 pellets.

Training. Training began on Day 13 and continued for 15 days. The rats were divided randomly into four groups of five per group. All rats ran the alley three times each day with runs terminating with 18,1 , or 0 food pellets. Monotonic (M) groups received the three runs in the 18-1-0 order. Nonmonotonic $(\mathrm{N})$ groups received the three runs in the 1-18-0 order. Massed (M) groups had a 15-20-sec IRI, and spaced (S) groups had a minimum of $4 \mathrm{~min}$ between runs. The four groups were designated MS, MM, NS, and NM.

The rats were run in four squads. Squad 1 had three MM rats and two NM rats, Squad 2 had three MS and two NS rats, Squad 3, two MM and three NM rats, and Squad 4, two MS and three NS rats. The squads were always run in the same order, with order of running within a squad varying over days. The rats in Squads 1 and 3 were run in rotation such that one rat received his three runs before the next rat was run, with the $15-20-\mathrm{sec}$ IRI. The rats in Squads 2 and 4 were run such that all rats in a squad received the first run before any received the second run. The IRI for these rats was a minimum of $4 \mathrm{~min}$; if the $4 \mathrm{~min}$ was not used the experimenter waited for this interval to elapse before proceeding further. The 4-min interval was specifically enforced for the first rat run in Squads 2 and 4 and was assumed to be in effect for the remaining four rats. A squad was fed its reduced ration of Lab Blox after the next squad was run-after approximately $15 \mathrm{~min}$. All rats in a squad spent the IRI in holding cages on a cart, where water was always available.

To begin a run, the rat was removed from the holding cage and placed in the startbox. About $3 \mathrm{sec}$ later, the startbox and goalbox doors were raised and the rat was allowed to run the alley. A maximum of $60 \mathrm{sec}$ was allowed per run. If the $60 \mathrm{sec}$ elapsed before the rat reached the goalbox, the rat was removed from the alley and placed gently in the goalbox. The rat was removed from the goalbox after all pellets had been eaten on rewarded runs or after $15 \mathrm{sec}$ on nonrewarded runs. An open canister of food pellets was placed near the goalbox, and pellets were poured into the foodcup from a cloth-lined paper cup.

\section{Results}

Figure 2 shows speed of running for each of the groups to each item of their series on Day 1 of training and thereafter in blocks of 2 days. An ANOVA revealed that no difference was significant on Day 1 . Over the subsequent days, differences did develop. By the final block, for ex-

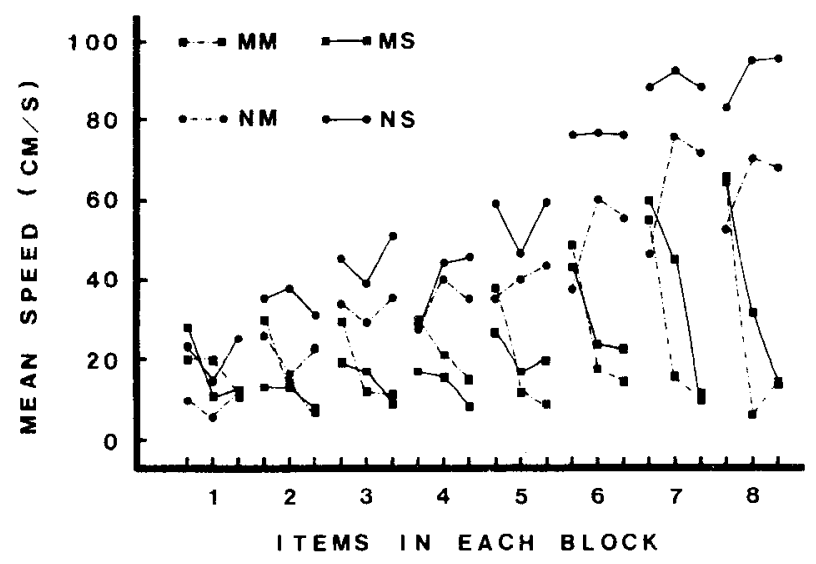

Figure 2. Running speeds for each of the four groups to each item of their series on Day 1 of training and thereafter in blocks of 2 days. In each block, the items are plotted either in the order 18-1-0 (M groups) or in the order 1-18-0 (N groups). 
ample, both monotonic groups anticipated each item of their series, running more rapidly to 18 pellets than to 1 or 0 pellets. But even by the final blocks, neither nonmonotonic group anticipated the 0-pellet item, running as rapidly to it as to 18 pellets. The only sign of anticipation in the nonmonotonic condition was in Group NM, which, over the last few blocks, ran more slowly to the 1-pellet item of the 1-18-0 series than to the 18-pellet item. Group NS ran equally rapidly to each item and quite rapidly overall. An ANOVA applied to Blocks 2-8 revealed that differences due to IRI fell short of being significant at the .05 level $[F(1,16)=2.75, .10>p>.05]$, that type of series, monotonic vs. nonmonotonic, had a highly significant effect on running speed $[F(1,16)=$ $35.97, \mathrm{p}<.001]$, and that running speed to the items differed as well $[\mathrm{F}(2,32)=15.61, \mathrm{p}<.001]$. Importantly for present purposes, the interaction of type of series, IRI, and items was highly significant $[F(2,3)=$ $48.29, \mathrm{p}<.001]$. Subsequent Newman-Keuls tests based on a breakdown of this interaction revealed the following within-group effects. Group NS ran equally rapidly to each of its items, but Group NM ran more slowly to its 1-pellet item than to either of its other items $(p<.01)$; no other within-group differences were significant. Thus, neither Group NS nor Group NM anticipated its 0-pellet item. Group MM ran more slowly to both its 1 - and 0 -pellet items than to its 18-pellet item $(p<.01)$; no other differences were significant. In Group MS, running was slower to the 1-pellet item than to the 18-pellet item and slower to the 0-pellet item that to the 1-pellet item (ps $<.01$ ).

As for between-group differences, Group NS ran faster to the first item of the series than did any of the remaining groups (ps $<.05$ ). On Run 3, the 0-pellet run for each group, each monotonic group ran more slowly than each nonmonotonic group (ps < .01), but no other difference was significant. With 1-pellet runs, each monotonic group ran more slowly than each nonmonotonic group (ps $<.01$ ), but no other differences were significant.

\section{Discussion}

By any definition, serial learning was better in the monotonic groups than in the nonmonotonic groups. For example, neither nonmonotonic group anticipated 0 pellets, whereas both monotonic groups did. That is, each monotonic group ran more slowly to its 0 -pellet item than to its 18-pellet item, but each nonmonotonic group ran equally rapidly to both of these items. Also, each monotonic group ran more slowly to 0 pellets than did each nonmonotonic group. There is some suggestion in the data obtained in Experiment 2 that serial learning was better at the shorter of the two IRIs. First, Group NM anticipated the 1-pellet item of its series but Group NS did not. Second, Group MM ran as slowly to its 1 pellet as it did to its 0-pellet item, but, although it anticipated both items. Group MS ran more rapidly to its 1 pellet than to its 0 -pellet item. These IRI-related differences were not large. but they contained at least the hint of a suggestion that running speed to smaller reward magnitude may tend to increase as IRI increases.

Fountain et al. (1983), employing conditions favorable for rule encoding, obtained better tracking of 0 pellets in the strongly monotonic 18-1-0 series than in the strongly nonmonotonic 1-18-0 series. They suggested that this finding, in and of itself, indicated that rats had opted for a rule-learning strategy in connection with the 18-1-0 series. Roitblat et al. (1983) also advanced arguments suggesting that the superior serial learning associated with the 18-1-0 series relative to the 1-18-0 series should not have been obtained in our Experiment 2, particularly at the 4-min IRI. The results obtained in Experiment 2 offer no support for these suggestions, since superior serial learning was associated with the $18-1-0$ series relative to the 1-18-0 series both under conditions deemed unfavorable for rule encoding (Experiment 2 here) and under conditions deemed favorable for rule encoding (Fountain et al., 1983).

\section{EXPERIMENT 3}

Roitblat et al. (1983) reported direct experimental evidence suggesting that the differences found between two serial learning groups when Hulse and Dorsky's (1977) experimental conditions were employed would not occur when the experimental conditions of Capaldi and Molina (1979) were used. The series employed by Roitblat et al. were the strongly monotonic series $14-7-3-1-0$ and the strongly nonmonotonic series 14-1-3-7-0. In the Hulse and Dorsky (1977) investigation, reliable tracking of 0 pellets began after about 4 presentations of the 14-7-3-1-0 series and after about 40 presentations of the 14-1-3-7-0 series, using an IRI of 10-15 sec, an ISI of about 10-15 min, four series presentations each day, and 68 series presentations overall. Roitblat et al. (1983), in their Experiment 1, compared the 14-7-3-1-0 and 14-1-3-7-0 series under two sets of experimental conditions. They employed conditions similar to those employed by Hulse and Dorsky (1977) and conditions like those employed by Capaldi and Molina (1979), one series presentation per day with an IRI of about 4-5 min. The 14-7-3-1-0 and 14-1-3-7-0 groups differed when the experimental conditions of Hulse and Dorsky (1977) were used, but not when the experimental conditions of Capaldi and Molina (1979) were used. On the basis of these findings, Roitblat et al. (1983) suggested that, under the two sets of experimental conditions they employed, two different and distinct types of serial learning tasks were involved, with a major factor being IRI.

We were not convinced that the results Roitblat et al. (1983) obtained in their Experiment 1 were representative and thus that they could justify any particular conclusion. Roitblat et al. (1983) failed to replicate Hulse and Dorsky (1977) in an important respect: Despite the fact that the nonmonotonic group of Hulse and Dorsky showed reliable and substantial tracking of 0 pellets following about 40 series presentations. the equivalent group of Roitbiat et al. showed no tracking of 0 pellets whatsoever 
within 60 series presentations. Nor did either of the groups trained with a 4-5 min IRI track 0 pellets. Although no direct comparisons with the 4-5 min groups of Roitblat et al. are available, a complete failure to track 0 pellets within 60 series presentations seems somewhat odd in view of the relative ease with which 0 pellets have been tracked under similar conditions in Experiment 2 both here and elsewhere (Capaldi \& Molina, 1979; Capaldi et al., 1980b). For reasons already mentioned, we do not think it is too much to suggest that, overall, tracking of 0 pellets was poor in all of the groups employed in Roitblat et al.'s Experiment 1. Accordingly, we decided to compare the monotonic group 14-7-3-1-0 and the nonmonotonic group 14-1-3-7-0 using one series presentation each day under a minimum 5-min IRI. Under these experimental conditions, according to Hulse and Roitblat, the monotonic group should not show better tracking of 0 pellets than the nonmonotonic group (see especially Roitblat et al., 1983).

\section{Subjects}

\section{Method}

The subjects were 12 rats of the same description as those employed in Experiment 2.

\section{Apparatus}

The apparatus was the same as that employed in Experiments 1 and 2 .

\section{Procedure}

Pretraining. Pretraining was as in Experiment 2, except that on Days 11-12 each rat received a single run in the alley, which terminated in 14 pellets.

Training. Training began on Day 13 and continued for 32 days. The rats were divided randomly into two groups of six each. All rats received five runs in the alley each day. Runs terminated in 14-7-3-1-0 pellets for Group $M$ and in 14-1-3-7-0 pellets for Group N. There were two squads of six rats each, three from each group. The running order of the rats was randomized daily. Each rat received the first run of the day before any rat received the second run, and so on. This generally produced an IRI of $5 \mathrm{~min}$ or more. If it did not, the experimenter was instructed to wait until $5 \mathrm{~min}$ had elapsed. All other aspects of the trainig procedure were as in Experiment 2.

\section{Results}

Figure 3 shows running speeds for Groups $M$ and $N$ to each of the items of their series in blocks of 4 days. On each of the initial two blocks of trials, Group $M$ ran more slowly than Group N. This was due in part to the fact that one rat in Group $M$ refused to run over the initial trials, although it ultimately performed as did the other rats in Group $M$. In any event, as may clearly be seen in Figure 3, over the last few blocks of trials, the two groups ran about equally rapidly to the first three items in their series, but to Item 4 and especially to Item 5 , a 0-pellet item in both series, Group $M$ ran more slowly than Group N. An ANOVA applied to the data shown in Figure 3 revealed the following. The groups did not differ significantly $[F(1,10)=2.60, \mathrm{p}>.10]$. Running speed to the items differed significantly $[F(4,40)=43.48$,

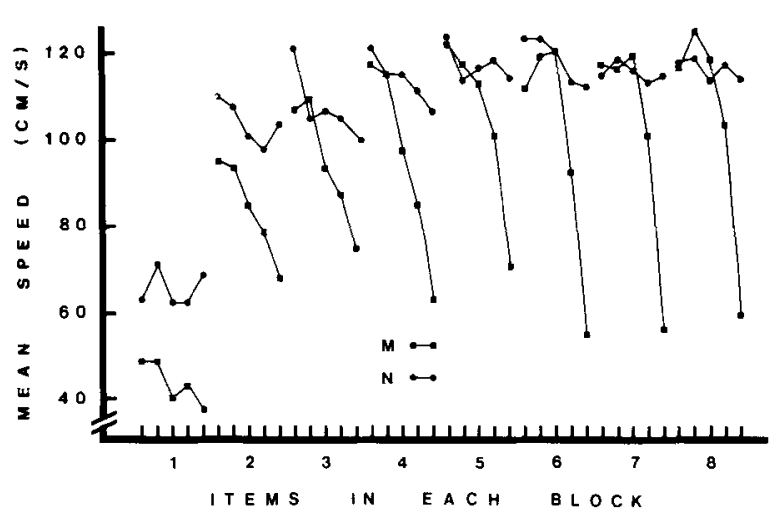

Figure 3. Running speeds for Groups $M$ and $N$ to each item in their series in blocks of 4 days. In each block, the items are plotted either in the order 14-7-3-1-0 (Group M) or in the order 14-1-3-7-0 (Group N).

$\mathrm{p}<.001$ ], and, importantly, the interaction of groups and items was highly significant $[F(4,40)=25.90$, $\mathrm{p}<.001]$. Newman-Keuls tests based on a breakdown of this interaction revealed that Group M's running speed to the 0-pellet item was slower than Group N's running speed to any item (ps $<.01$ ). Also, Group M ran more slowly to its 0-pellet item than to any other item in its series (ps either .05 or .01 ). No other difference, either within or between groups, was significant. Additionally, the groups $\times$ items $\times$ blocks interaction was significant $[\mathrm{F}(28,280)=2.50, \mathrm{p}<.001[$. Newman-Keuls tests based on this interaction revealed the following withingroups differences for the 0-pellet item. Group $M$ ran more slowly to its 0-pellet item than it did to items 1,2, and 3 on Block 2 (all ps < .05) or to items 1-4 on Blocks 3-8 (all ps < .01). However, Group N showed little evidence of anticipation, running more slowly to its 0 -pellet items than to its 14-pellet item only on Block 3 ( $p<.05$ ). Between-groups differences on the 0-pellet item revealed that Group $M$ ran significantly more slowly than Group $\mathrm{N}$ on all blocks (all ps $<.05$ ).

\section{Discussion}

Hulse and Dorsky (1977), employing the 14-7-3-1-0 and 14-1-3-7-0 series under conditions favorable for rule encoding, obtained tracking of 0 pellets under both series, although it was better in the 14-7-3-1-0 series. This finding was attributed to rule encoding. However, in Experiment 3 here, employing experimental conditions which, according to Hulse (1980), should promote associative learning rather than rule encoding, we nevertheless obtained better tracking of 0 pellets under the 14-7-3-1-0 series than under the 14-1-3-7-0 series. Thus, the findings obtained in Experiment 3 do not support the hypothesis, suggested by Hulse (1980), that better tracking of 0 pellets in the 14-7-3-1-0 series than in the 14-1-3-7-0 series depends upon employing a short IRI of $15-20 \mathrm{sec}$, an ISI of 10-15 min, and as many as four series presentations each day. That tracking of 0 pellets did not occur in Experiment 3 under the 14-1-3-7-0 series within the 
32 series presentations employed was not surprising: As indicated, tracking of 0 pellets under this series did not occur in the Hulse and Dorsky investigation prior to about 40 series presentations.

According to Roitblat et al. (1983), better serial learning of the 14-7-3-1-0 series than of the 14-1-3-7-0 series should not occur when the IRI is as long as $5 \mathrm{~min}$. The results obtained in Experiment 3 are incompatible with this suggestion and, moreover, fail to replicate findings of Roitblat et al. (1983), who reported no difference in serial learning, in their Experiment 1, between the 14-73-1-0 and 14-1-3-7-0 series at a 4-5 min IRI. What accounts for the discrepancy between our findings and those of Roitblat et al. (1983)? Our hypothesis, outlined in the introductory comments to this experiment, is that tracking of 0 pellets was generally poor in Roitblat et al.'s (1983) investigation. One possibility suggested by Roitblat (personal communication, March 1984) is that, for one or more of several reasons, his rats may have been poor at serial learning. He indicated that his rats were much older than ours, 7-8 months versus 3 months, that they had been employed in previous operant conditioning exercises whereas ours were naive, and that they were of a different strain, Charles River versus the Holtzman rats we employed.

\section{GENERAL DISCUSSION}

According to Hulse's rule-encoding model, strongly monotonic decreasing series should be learned more rapidly than either a mildly monotonic series or a nonmonotonic series. However, Capaldi and Molina (1979) and Capaldi et al. (1980b) reported a number of instances in which strongly monotonic series were learned less well than either mildly monotonic or nonmonotonic series. These findings, according to Hulse (1980) and Roitblat (1982; see also Roitblat et al., 1983), are not inconsistent with Hulse's rule-encoding formulation. These findings, rather, are said to be associated with a set of experimental conditions that are favorable to associative learning but not to rule encoding: a relatively long IRI (e.g., $5 \mathrm{~min}$ ), a relatively long ISI (e.g., $24 \mathrm{~h}$ ), too few series presentations each day (e.g., only one), relatively short series of only two or three items, and, finally, insufficient training. If this suggestion is correct, then the differences obtained in each of the three investigations reported here should not have been obtained. First, although the differences obtained in our present Experiment 1 were supposedly associated with experimental conditions favorable only for associative learning, we obtained them under conditions supposedly favorable for rule encoding. Moreover, although the differences obtained in our Experiments 2 and 3 were supposedly associated with experimental conditions favorable only for rule encoding, we obtained them here under conditions supposedly favorable for associative learning. Thus, what emerges from a comparison of the present findings with earlier ones is that the distinction between experimental conditions favorable for rule encoding and experimental conditions favorable for associative learning is not supported by the available evidence. On the contrary, a comparison of the present findings with earlier ones suggests that the differences obtained between two or more serial learning groups are relatively invariant over a wide range of experimental conditions. Whether more extreme values of the variables employed here, for example, an IRI of $24 \mathrm{~h}$, would reduce or eliminate the sorts of differences reported here is, of course, an open question.

What are the implications for the rule-encoding view in demonstrating, as in the three investigations reported here, that differences between two or more serial learning groups are relatively invariant over a wide range of experimental conditions? One alternative for the ruleencoding view is to accept this proposition, dropping the emphasis on conditions favorable for rule encoding versus conditions favorable for associative learning. With this approach, the results obtained in our Experiments 2 and 3 , in which strongly monotonic groups demonstrated better serial learning than strongly nonmonotonic groups, would be seen as consistent with the rule-encoding view despite the fact that conditions previously said to be favorable for associative learning were employed in the investigations. The problem with this approach for the rule-encoding model is that it does not provide a basis for explaining the wide variety of findings that contradict it, including those reported in Experiment 1 here and those reported by Capaldi and Molina (1979) and Capaldi et al. (1980b). Whatever the resolution of this theoretical difficulty within the rule-encoding framework, it does not seem to lie with emphasizing such variables as IRI, ISI, the number of items in the series, the number of series presentations each day, and amount of training (see Hulse, 1980; Roitblat, 1982; Roitblat et al., 1983).

Is there some single model that is consistent with all available serial learning data? We suggest that there is-a memory model that assumes that the signal for any item in a series is the memory of the prior item either by itself or in combination with the memory of one or more previous items (Capaldi \& Molina, 1979; Capaldi, Nawrocki, \& Verry, 1982, 1983; Capaldi \& Verry, 1981; Capaldi et al., 1980a, 1980b; Capaldi, Verry, \& Nawrocki, 1982; Capaldi, Verry, Nawrocki, \& Miller, 1984; see also Yazawa \& Fujita, 1984). Before indicating how the memory model would explain the findings in each of the investigations reported here, let us be abundantly clear on one point. The ability or lack of ability of the memory model to explain the present findings has nothing whatever to do with the major thrust of this report, which is that differences between two or more serial learning groups appear to be invariant over a wide range of experimental conditions rather than, as suggested by Hulse and Roitblat, being tied to specific sets of experimental conditions.

According to the memory view, serial learning is a variety of discrimination learning in that the animal must learn which memories signal which items. Of major concern in the investigations examined below was the 
animal's anticipation of a terminal 0-pellet item, as indexed by slow running. Whether this item will prove easy or hard to anticipate depends upon whether it is embedded in an easy or hard discrimination-learning problem. Deciding whether a problem in serial learning is hard or easy is no different from deciding whether a problem in conventional discrimination-learning situations is hard or easy (see, e.g., Capaldi \& Molina, 1979; Capaldi et al., 1980a). Consider two examples: the 15-10-5-0 series versus the 15-15-0-0 series (Experiment 1 here and in Capaldi \& Molina, 1979) and the 20-10-0 series versus the 1-29-0 series (Experiment 2 in Capaldi \& Molina, 1979). In the 15-10-5-0 series, the signal for 0 pellets, the memory of 5 pellets or $5^{\prime}\left(5^{\prime} \rightarrow 0\right)$, is similar to the signals for relatively large rewards, $15^{\prime} \rightarrow 10$ and $10^{\prime} \rightarrow 5$. In the 15-15-0-0 series, however, the signal for the terminal 0 -pellet item, $0^{\prime}\left(0^{\prime} \rightarrow 0\right)$ is quite dissimilar from the memory that signals large reward, since $15^{\prime}-15$. Consistent with this analysis, 0 pellets was more easily anticipated in the 15-15-0-0 series than in the 15-10-5-0 series. Easier anticipation of 0 pellets occurred in the 1-29-0 series than in the 20-10-0 series for the same reason. That is, it is easier to discriminate between two dissimilar cues, $1^{\prime} \rightarrow 29$ and $29^{\prime} \rightarrow 0$ (the 1-29-0 series), than between two similar cues, $20^{\prime} \rightarrow 10$ and $10^{\prime} \rightarrow 0$ (the 20-10-0 series).

Consider now the series employed in Experiment 2, 18-1-0 and 1-18-0. In the 18-1-0 series, we have $18^{\prime} \rightarrow 1$ and $1^{\prime} \rightarrow 0$, and in the 1-18-0 series, we have $1^{\prime} \rightarrow 18$ and $18^{\prime}-0$. In both series, then, the same item memories, $18^{\prime}$ and $1^{\prime}$, are employed as discriminative cues. The important difference is this: In the 18-1-0 series, both memories signal small reward $\left(18^{\prime} \rightarrow 1\right.$ and $\left.1^{\prime} \rightarrow 0\right)$, and thus both memories are inhibitory (see Capaldi et al., 1982). However, in the 1-18-0 series, one memory signals small reward and the other signals large reward $\left(1^{\prime} \rightarrow 18\right.$ and $\left.18^{\prime} \rightarrow 0\right)$. It may be seen that because of stimulus generalization between 18' and $1^{\prime}$, the 18-1-0 series clearly involves an easier discrimination learning problem than does the 1-18-0 series. In the 18-1-0 series, inhibitory tendencies generalize from $18^{\prime}$ to $1^{\prime}$ and from $1^{\prime}$ to $18^{\prime}$, and so mutually reinforce each other. But, in the 1-18-0 series, although inhibitory tendencies generalize from $18^{\prime}$ to $1^{\prime}$, excitatory tendencies generalize from $1^{\prime}$ to $18^{\prime}$, increasing running speed in the presence of $18^{\prime}$ and so decreasing tracking of the 0 -pellet item. Finally, the memory view suggests that the 14-7-3-1-0 series employed in Experiment 3 contains an easier discrimination problem than does the 14-1-3-7-0 series. In the 14-7-3-1-0 series, $1^{\prime} \rightarrow 0$ and the highly dissimilar cue, $14^{\prime}$, signals the relatively large reward, 7 pellets. But in the 14-1-3-7-0 series, $7^{\prime} \rightarrow 0$, and a relatively similar cue, $3^{\prime}$, signals the relatively large reward, 7 pellets, creating a relatively difficult discrimination learning problem. In other respects, the two series are of about equivalent difficulty, for example, 14 pellets is the first item in each of the series, and so on.

Animals given original training on one series may, in a subsequent phase, be shifted to another series, which might include a series of 0-pellet trials or be an extinction series (e.g., Capaldi et al., 1980b; 1984; Hulse \& Dorsky, 1979). Our view of such transfer effects, outlined in some detail in the papers cited, may be sum. marized in general terms. A memory occurring in trans. fer may be the same as that which occurred in original learning, or be similar to it. That memory will give rise in the early stages of transfer, to the same sort of antici. pation as it did in original learning and thus to the same sort of behavior. For example, if a 0-pellet item was : signal for large reward in original learning, the animal on being shifted to a series of 0 -pellet items (extinction). would continue to anticipate large reward for some num. ber of trials and so run rapidly (Capaldi et al., 1984). This sort of analysis has been successfully applied to shifts from monotonic to nonmonotonic series and vice versa (Capald; et al., 1980a).

\section{REFERENCES}

Capaldi, E. J., \& Molina, P. (1979). Element discriminability as : determinant of serial-pattern learning. Animal Learning \& Behavior 7, 318-322.

Capaldi, E. J., Nawrocki, T. M., \& Verry, D. R. (1982). Difficul serial anticipation learning in rats: Rule encoding vs. memory. Anima Learning \& Behavior, 10, 167-170.

Capaldi, E. J., Nawrocki, T. M., \& Verry, D. R. (1983). The na ture of anticipation: An inter- and intraevent process. Animal Learn ing \& Behavior, 11, 193-198.

CAPAld, E. J., \& VerRY, D. R. (1981). Serial order anticipation learning in rats: Memory for multiple hedonic events and their order. Anima, Learning \& Behavior, 9, 441-453.

Capaldi, E. J., Verry, D. R., Davidson, T. L. (1980a). Memory, serial anticipation pattern learning, and transfer in rats. Animal Learning \& Behavior, 8, 575-585.

Capaldi, E. J., Verry, D. R., \& Davidson, T. L. (1980b). Why rule encoding by animals in serial learning remains to be established. Anima Learning \& Behavior, 8, 691-692.

Capaldi, E. J., Verry, D. R., Nawrocki, T. M. (1982). Multiple hedonic memory: Memory for more than one hedonic event in the rat. Animal Learning \& Behavior, 10, 351-357.

Capaldi, E. J., Verry, D. R., Nawrocki, T. M., \& Miller, D. J. (1984). Serial leaming, interitem associations, phrasing cues, interference, overshadowing, chunking, memory, and extinction. Animai Learning \& Behavior, 12, 7-20.

Fountain, S. B., Evensen, J. C., \& Hulse, S. H. (1983). Formal structure and pattern length in serial pattern learning by rats. Animai Learning \& Behavior, 11, 186-191.

Hulse, S. H. (1980). The case of the missing rile: Memory for reward vs. formal structure in serial-pattern learning by rats. Animal Learning \& Behavior, 8, 689-690.

Hulse, S. H., \& DoRSKY, N. P. (1977). Structural complexity as a determinant of serial pattern learning. Learning \& Motivation, 8 , 488-506.

HULSE, S. H., \& DoRSKY, N. P. (1979). Serial pattern learning by rats: Transfer of a formally defined stimulus relationship and the significance of nonreinforcement. Animal Learning \& Behavior, 7, 211-220.

Roitblat, H. L. (1982). The meaning of representation in animal memory. Behavioral and Brain Sciences, 5, 353-371.

Roitblat, H. L., Polage, B., \& Scopatz, R. A. (1983). The representation of items in serial position. Animal Learning \& Behavior, 11 , 489-498.

YaZAWA, H., \& FujiTA, O. (1984). Reinforcement pattern learning: Do rats remember all prior events. Animal Learning \& Behavior, 12, 383-390.

(Manuscript received August 23, 1984; revision accepted for publication January $11,1985$. ) 